\title{
AVALIAÇÃO QUALI-QUANTITATIVA DA ARBORIZAÇÃO DAS PRAÇAS DO BAIRRO JARAGUÁ, UBERLÂNDIA - MG.
}

\author{
Tiago Martins Rezende1; Douglas Gomes dos Santos ${ }^{2}$ \\ (recebido em 14.09.2009 e aceito para publicação em 10.06.2010)
}

\section{RESUMO}

A arborização das praças do bairro Jaraguá foi analisada quali-quantitativamente utilizandose levantamento arbóreo, análise da altura e condições físico sanitárias. Foi observada a presença de flores e frutos para constatar a capacidade de atração e manutenção da fauna local. Foram encontrados 196 indivíduos distribuídos em 21 espécies (11 nativas e 10 exóticas). As cinco espécies mais frequentes representaram $72,94 \%$ do total de plantas levantadas, sendo a espécie Callistemon speciosus (Sims) Sweet. a mais abundante, com $28,57 \%$. Das espécies, 63,73 \% são exóticas e a maioria das nativas se encontra representadas por um, dois e três indivíduos, tornando as praças pouco eficientes na atração e manutenção da fauna local. A altura predominante foi a de médio porte (78 indivíduos). O reduzido número de mudas mostra a falta de participação da comunidade na arborização local. As plantas estão em boas condições $(75,17 \%)$, porém foram constatados danos físicos por vandalismo e podas inadequadas, indicando a necessidade de um programa de educação ambiental e de um plano diretor para arborização urbana.

Palavras chave: arborização urbana; espaços livres de construção; qualidade ambiental.

\footnotetext{
${ }^{1}$ Biólogo, Especialista em Gestão Ambiental, Rua das Seringueiras, nº 533, B. Jaraguá - Uberlândia MG. CEP: 38413-024. Email: tiagomr7@yahoo.com.br

${ }^{2}$ Geógrafo, Professor Doutor, Instituto de Geografia - UFU - Uberlândia/MG. Email: douglasantos@ig.ufu.br
} 


\section{QUALITATIVE-QUANTITATIVE ASSESSMENT OF TREES IN SQUARES IN JARAGUA NEIGHBORHOOD - UBERLANDIA / MG}

\section{ABSTRACT}

Urban trees in Jaragua neighborhood squares were qualitative and quantitative analyzed by means of tree inventory, analysis of height and physical health conditions. Presence of flowers and fruits was observed analyzing ability to attract and keep the local fauna. 196 individuals in 21 species were found (11 native and 10 exotic). The five most common species accounted for $72.94 \%$ of all plants raised, and the species Callistemon speciosus (Sims) Sweet. The most abundant with 28.57\%. 63.73\% species are exotic, and most native are represented by one, two and three individuals, making the squares not efficient in attracting and retaining the local fauna. The height was the predominant medium size (78 individuals). The low number of seedlings shows a lack of community participation in urban trees site. The plants are in good condition (75.17\%), but were found physical damage from vandalism and improper pruning, indicating the need for an environmental education program and a master plan for the urban trees.

Keywords: environmental quality; open spaces; urban trees. 


\section{INTRODUÇÃO}

A população brasileira cresceu 8,48\% nos últimos sete anos, segundo o censo 2007 realizado pelo IBGE. Em 2000, eram 169.799.170 habitantes, alcançando 183.987.291 habitantes em 2007 (IBGE, 2007). A estimativa da população urbana realizada em 2006 mostra um índice de $89,1 \%$, sendo esse alto índice demográfico em área urbana um agravante aos problemas socioambientais urbanos, tais como a produção de lixo, esgotos e a poluição da água, do solo e da atmosfera (SILVA, 2005). O ambiente urbano é intensamente alterado, devido aos atuais modelos de edificações e loteamento do solo que restringem os espaços determinados às áreas verdes. Essas restrições limitam a utilização de árvores na Floresta Urbana, em relação ao seu porte e à quantidade de espécies (YAMAMOTO et al., 2004).

Com a crescente urbanização das cidades, a preservação, recuperação e criação de espaços verdes urbanos são as grandes preocupações de estudiosos e planejadores urbanos, já que tais espaços são fundamentais para a qualidade ambiental e de vida da população (MILANO; DALCIN, 2000; SILVEIRA; BARROS, 2001). Dentre as medidas importantes para reduzir os impactos ambientais urbanos estão a arborização urbana e a criação de áreas verdes (MILANO, 1987). Em Uberlândia, a criação de áreas verdes, principalmente parques e praças, não acompanhou o rápido crescimento da população, fazendo com que o Índice de Área Verde (IAV) por habitante caísse de 7,6 $\mathrm{m}^{2}$ por habitante em 2000 (TOLEDO et al., 2009) para 4,9 m² por habitante, em 2007 (SANTOS et al., 2009).

A maioria das prefeituras dos municípios brasileiros não se preocupa com o planejamento da arborização, o que leva os próprios moradores, muitas vezes, a realizarem o plantio nas áreas públicas. Desse modo, o padrão observado em muitas cidades brasileiras é de uma arborização irregular, inadequada e descontínua (SILVA et al., 2008b), ocorrendo, em muitos, casos o plantio de espécies exóticas.

Os municípios brasileiros se constituem de áreas urbanas, com expansão e de rural. Nas áreas urbanas estão os espaços de integração urbana (rede rodo ferroviária, espaços com construções, habitações, indústrias, comércio, hospitais, escolas, etc.) e de espaços livres de construção (praças, parques, águas superficiais, etc.). Embora quase todas as cidades brasileiras tenham praças, parques e outras áreas onde a população possa ter momentos de lazer e desfrutar a estética da natureza, poucas possuem esses espaços organizados, tornando-os apenas espaços abertos ao ar livre sem nenhuma proposição ambiental e de uso público (CAVALHEIRO; DEL PICCHIA, 1992; GRIFFITH; SILVA, 1987).

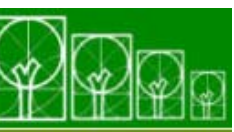

$\mathbf{S} \cdot \mathbf{B} \cdot \mathbf{A} \cdot \mathbf{U}$ Soc. Bras. de Arborização Urbana 


\section{Benefícios das áreas verdes no espaço urbano}

As áreas verdes têm papel fundamental na qualidade de vida da população e na redução dos impactos ambientais urbanos (SILVA, 2005; TOLEDO; SANTOS, 2008). Dentre os inúmeros benefícios das áreas verdes destacam-se:

- a capacidade de absorção dos raios solares, proporcionando sombreamento;

- a manutenção do equilíbrio microclimático por meio da diminuição da amplitude térmica e aumento da umidade relativa do ar em consequência da evapotranspiração;

- a absorção de $\mathrm{CO}_{2}$ e retenção de partículas sólidas em suspensão;

- a estabilidade geomorfológica por meio da fixação do solo pelas raízes das plantas evitando erosões;

- $\quad$ a redução da velocidade do vento;

- a proteção da qualidade da água, pois impedem que substâncias poluidoras escorram para os rios;

- a redução da poluição sonora pela barreira que as árvores exercem à propagação do som;

- abrigo para fauna urbana, principalmente aves, insetos e fauna do solo;

- a valorização estética e paisagística do local;

- a redução do impacto das chuvas e o aumento das áreas de infiltração, tendo em vista que a impermeabilização crescente e progressiva do solo aumenta o escoamento superficial, não tendo a rede de captação de águas pluviais capacidade suficiente para escoar de modo rápido o grande volume de água que faz transbordar os córregos e se acumula nos vales do sítio urbano.

Além dos benefícios social, ecológico e estético, as áreas verdes também podem auxiliar na educação e na melhoria da saúde física e mental da população, devido às vantagens do elemento anti-stress e o relaxamento proporcionado pelo contato com a natureza (GRIFFITH; SILVA, 1987; OLIVEIRA, 1996; MILANO; DALCIN, 2000; NUCCI, 2001; ROCHA et al., 2004).

\section{A importância das praças}

As praças são espaços livres urbanos utilizados como local público. Elas são pontos de encontro, cujas principais funções são de incentivar a vida comunitária e o lazer, e para

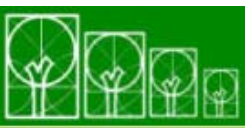


se constituírem como área verde, devem ser arborizadas e livres de impermeabilização (LIMA et al., 1994b; DEMATTÊ, 1997). São áreas verdes com dimensões em geral entre $100 \mathrm{~m}^{2}$ e 10 hectares.

As praças também configuram como um local estratégico para o planejamento da arborização urbana, visto que são locais de menor confronto com as construções urbanas e com as redes de transmissão de energia. Outro aspecto de destaque é o seu tamanho, que geralmente é pequeno, possibilitando maior distribuição pela cidade, permitindo a proximidade das áreas verdes a um maior número de habitantes. Nesse sentido, Machado (1995, p. 274) lembra que: "O Código Civil brasileiro não só utiliza o termo "praça", como classifica o bem como público, definindo sua natureza - bem de uso comum do povo (art. 66, I)".

A Lei de parcelamento do solo urbano (Lei $n^{0}$ 6.766/79) estabelece que:

Os espaços livres de uso comum, as vias e as praças, as áreas destinadas a edifícios públicos e outros equipamentos urbanos, constantes do projeto e do memorial descritivo, não poderão ter sua destinação alterada pelo loteador, desde a aprovação do loteamento, salvo as hipóteses de caducidade da licença ou desistência do loteador, sendo neste caso, observadas as exigências do art. 23 desta Lei.

\section{A arborização urbana}

A arborização urbana e os elementos existentes nos centros urbanos (postes de iluminação pública, fiações, telefones públicos, placas de sinalização entre outros), convivem em desarmonia devido à ausência de planejamento tanto da arborização, quanto dos outros componentes desse espaço (YAMAMOTO et al., 2004). A arborização urbana apresenta vários aspectos qualitativos e quantitativos, que devem ser mensurados no planejamento.

O caráter qualitativo da arborização refere-se à escolha da(s) espécie(s) mais adequada(s) a cada espaço da cidade como ruas, parques, praças, alamedas, considerando, sempre, as condições edafoclimáticas e físicas locais. O caráter quantitativo, qualquer que seja, é insatisfatório se não vier acompanhado por parâmetros de qualidade da(s) espécie(s) em questão ou, segundo Griffith e Silva (1987), a melhor maneira de avaliar um sistema de áreas verdes não é necessariamente a quantidade de espaço verde por

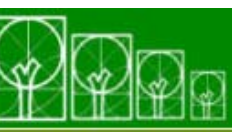

$\mathbf{S} \cdot \mathbf{B} \cdot \mathbf{A} \cdot \mathbf{U}$ Soc. Bras. de Arborização Urbana 
habitante, uma vez que aspectos como a forma, a qualidade e a distribuição das áreas são subjetivos, e tão fundamentais quanto à quantidade.

\section{Introdução de espécies exóticas}

Os conceitos de espécie nativa ou exótica são usados, em geral, como sinônimos de nacional e estrangeira, o que não faz muito sentido, já que as espécies não se distribuem de acordo com as divisões político-geográficas humanas. Em alguns casos, esse conceito é estendido para unidades geográficas ainda maiores, considerando-se exóticas as espécies vindas de outros continentes, ou mesmo de outra região do Brasil (SANTOS et al., 2008).

A implantação de árvores na paisagem urbana, quando realizada de forma planejada, tende a proporcionar somente benefícios. A exceção ocorre àquelas espécies com capacidade de realizar invasão biológica, denominadas atualmente "exóticas invasoras". Invasão biológica é a introdução e a adaptação de espécies que não fazem parte, naturalmente, de um dado ecossistema, mas que se adaptam e passam a provocar mudanças em seu funcionamento, como a competição com as espécies nativas por polinizadores e dispersores de frutos e sementes, a redução da variabilidade genética e até mesmo a extinção local de determinada espécie (ZILLER, 2001).

\section{MATERIAIS E MÉTODOS}

\section{Caracterização da área de estudo}

A cidade de Uberlândia (MG) está localizada no oeste do Estado de Minas Gerais, na região do Triângulo Mineiro, na intersecção das coordenadas geográficas de 1855'23" S e 48 17'9" W. A área territorial do município é de $4.115 \mathrm{~km}^{2}$, sendo que $219 \mathrm{~km}^{2}$ correspondem ao perímetro urbano, com população estimada acima de 600 mil habitantes. (BRITO; PRUDENTE, 2005; IBGE, 2007).

O município de Uberlândia está inserido no Bioma Cerrado, e a cobertura vegetal da região está restrita a pequenas reservas isoladas dentro de uma matriz de atividades agropecuárias e reflorestamentos. A cobertura vegetal natural (cerrado, mata, campo hidromórfico, de várzea e campos hidrófilos) do município de Uberlândia ocupa 17,7\% da área total, enquanto que a área urbana ocupa 4,6\% (ARAÚjo et al., 1997; ARAÚjO et al., 2002; BRITO; PRUDENTE, 2005).

De acordo com a classificação dos macroclimas do Brasil, a cidade de Uberlândia, está localizada numa região de clima subquente, de variedade Cwa, com médias térmicas 
variando anuais de $19^{\circ} \mathrm{C}$ a $27^{\circ} \mathrm{C}$ e pluviosidade média em torno de $1500 \mathrm{~mm} / \mathrm{ano}$ (SILVA; ASSUNÇÃO, 2004).

O bairro Jaraguá está situado no setor oeste da cidade de Uberlândia-MG, margeando o lado esquerdo do rio Uberabinha. Apresenta área de $1.637 \mathrm{~km}^{2}$, população de 10.043 habitantes e se caracteriza como residencial e comercial, (padarias, bares, farmácias, mercados e oficinas) (SECRETARIA MUNICIPAL DE PLANEJAMENTO URBANO E MEIO AMBIENTE - SEPLAMA / estimativa 2007). O bairro possui cinco praças com diferentes tamanhos e formatos.

Foram realizadas pesquisas de campo nas cinco praças existentes no bairro Jaraguá, durante os meses de setembro e novembro de 2008. As praças presentes no bairro são: Praça Gefferson Guimarães da Silva (Ge); Praça das Rosas (Ro); Praça Montese (Mo); Praça Sgt. Ariston de S. Milhomen (Sgt); Praça Rita F. Huguiney (Ri). As praças foram nomeadas conforme consta nas placas da prefeitura de Uberlândia, e a localização de cada uma delas está representada na Figura 1.

$\mathrm{Na}$ pesquisa de campo, também se utilizou uma ficha de levantamento arbóreo, elaborada com as seguintes informações sobre a praça: nome; localização; características. Em relação aos organismos arbóreos encontrados, foram relacionadas as seguintes informações: nome popular; quantidade $\left(\mathrm{n}^{0}\right)$; tamanho (porte); observações (características da espécie). Nas informações sobre o porte, as espécies foram caracterizadas como: muda (até $1 \mathrm{~m}$ de altura); pequeno porte (altura entre 1,01 m e $3 \mathrm{~m}$ ); médio porte (altura entre $3 \mathrm{~m}$ a $6 \mathrm{~m}$ ); e grande porte vegetal (com mais de $6 \mathrm{~m}$ ).

Em relação à qualificação, os espécimes encontrados foram caracterizados como: boa; satisfatória; ruim; morta. 


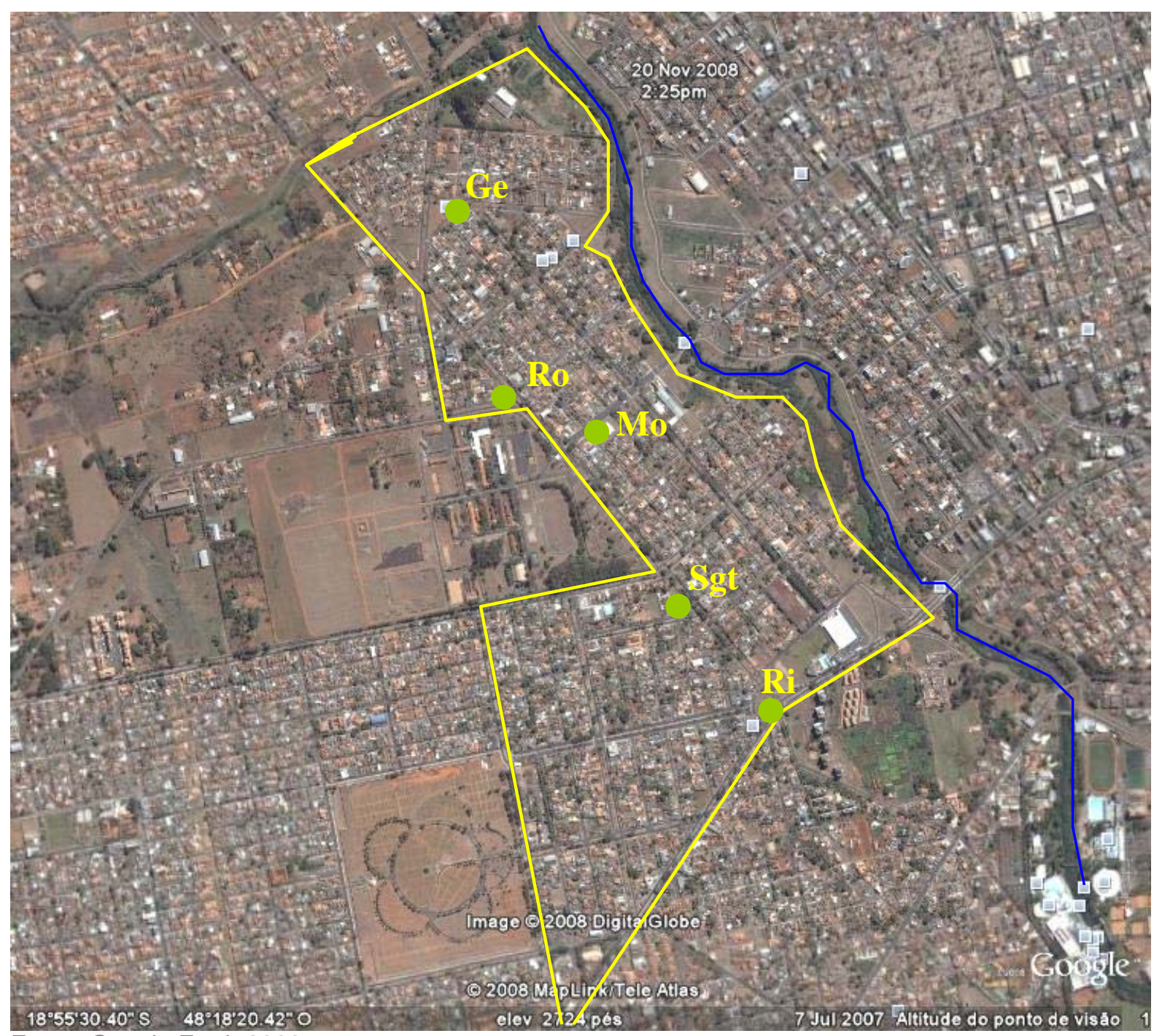

Fonte: Google Earth 2008.

FIGURA 1 - Delimitação do bairro Jaraguá (amarelo), rio Uberabinha (azul), e localização das praças (verde): Gefferson Guimarães da Silva (Ge); das Rosas (Ro); Montese (Mo); Sgt. Ariston de S. Milhomen (Sgt); Rita F. Huguiney (Ri).

\section{Levantamento quantitativo das espécies arbóreas}

Todos os indivíduos vegetais presentes nas praças foram contados e fotografados para identificação. As fotos contemplavam as seguintes características: folhas e flores, quando existente. $\mathrm{Na}$ identificação das espécies e origem, foram realizadas comparações entre as fotografias com imagens de endereços eletrônicos e bibliografias específicas. No período de setembro a novembro de 2008 , foi observada a presença de flores e frutos para avaliar a atração e manutenção da fauna local. 
A frequência (\%) relativa de cada espécie foi calculada através da razão entre o número de indivíduos da espécie e o número total de indivíduos de todas as praças, multiplicada por 100 (ROCHA et al., 2004).

As espécies encontradas e identificadas foram separadas quanto sua origem, de acordo com a seguinte classificação:

1. Exótica: espécie que não ocorre espontaneamente no Bioma onde a cidade de Uberlândia está inserida.

2. Nativa: espécie que ocorre espontaneamente no Bioma em que a cidade de Uberlândia está inserida.

\section{Levantamento qualitativo das espécies arbóreas}

A classificação da altura da vegetação arbórea seguiu o método adaptado de Santos e Teixeira (2001), ou seja:

- $\quad$ muda - vegetal com até $1 \mathrm{~m}$ de altura;

- pequeno porte - vegetal com altura entre 1,01 m e $3 \mathrm{~m}$;

- médio porte - vegetal com altura entre $3 \mathrm{~m}$ e $6 \mathrm{~m}$ e

- grande porte - vegetal com mais de $6 \mathrm{~m}$.

Na avaliação dos aspectos físicos sanitários, foi utilizada a metodologia de Santos e Teixeira (1991), considerando a seguinte classificação:

1. Boa - isenta de sinais de pragas, doenças ou injúrias mecânicas. Apresenta forma característica da espécie.

2. Satisfatória - apresenta pequenos problemas de pragas, doenças ou danos físicos. Necessita de poda corretiva.

3. Ruim - apresenta severos danos de pragas, doenças ou danos físicos. Requer muito trabalho para recuperação.

4. Morta - ou que apresente morte iminente.

\section{RESULTADOS E DISCUSSÕES}

Foram encontrados 196 indivíduos arbóreos, distribuídos em 21 espécies, sendo cinco espécies responsáveis por $72,94 \%$ das plantas levantadas. Tal fato também foi observado por Santos e Teixeira (1990), que constataram cinco espécies abrangendo mais de $70 \%$ da arborização do bairro Centro, cidade de Santa Maria - RS.

É comum na arborização urbana ocorrer poucas espécies representando a maioria da população, mesmo não sendo uma situação desejável, quer por razões estéticas ou fitossanitárias (SILVA, 2000). Na arborização de cidades brasileiras, observa-se certa 
uniformidade quanto ao emprego de algumas espécies, o que se pode supor ser consequência normal de uma cidade procurar, na maioria das vezes, imitar a arborização de outra, fato que pode explicar a baixa diversidade, concentrando-se a maioria em um número reduzido de espécies (SOUZA, 1994 apud CRUZ et al., 2008).

Das cinco praças presentes no bairro Jaraguá, houve o predomínio de Callistemon speciosus (escova-de-garrafa) em três delas, correspondendo com média de 22,2 \% dos indivíduos presentes nas três praças e $28,57 \%$ do total de indivíduos (Tabela 1). O plantio de Callistemon speciosus é realizado pela Prefeitura Municipal de Uberlândia (PMU), constituindo-se na principal razão da alta frequência da espécie e mostrando não existir planejamento da arborização para a cidade, o que gera baixa diversidade e alta concentração de indivíduos de uma mesma espécie.

A alta concentração de indivíduos distribuídos num pequeno número de espécies também foi encontrada por Milano (1988), no inventário da cidade de Maringá - PR, por Lima et al. (1994a) na cidade de Piracicaba - SP, assim como na cidade de Porto Alegre RS (PORTO ALEGRE, 2000).

De acordo com Grey e Deneke (1986), é aconselhável que as espécies de maior frequência não ultrapassem os $15 \%$ do total, visto que porcentagens mais elevadas aumentam o risco da ocorrência de pragas e doenças. Deve-se evitar a arborização de um bairro ou cidade com uma única espécie (GRAZIANO, 1994 apud DANTAS e SOUZA, 2004). Com o presente trabalho, observou-se que, na cidade de Uberlândia, a frequência de determinadas espécies supera, em muito, esta sugestão.

A introdução de espécies exóticas na arborização urbana no Brasil é bastante comum. Como exemplo, cita-se a cidade de Maringá (PR), que está entre as mais arborizadas do país, onde $24,1 \%$ das árvores são nativas. É possível elencar outros exemplos de frequência de espécies exóticas no ambiente urbano, como a cidade do Rio de Janeiro - RJ (84,7\%), Assis - SP (61,82\%), Campina Grande - PB (50,7\%) e Goiandira - GO (50\%). Outro fato é o plantio incentivado pelo comércio ornamental e produção de mudas de plantas invasoras ou potencialmente invasoras (Horto Municipal de Uberlândia - MG, Horto Municipal de Barreirinha em Curitiba - PR) (ZILLER, 2001; DANTAS; SOUZA, 2004; PIRES et al., 2007; BIONDI; LEAL, 2008; BLUM et al., 2008; SANTOS et al., 2008).

As ações de arborização poderiam contribuir com a recuperação do patrimônio de biodiversidade natural que foi dilapidado no processo de fundação e expansão das cidades (REIS et al., 2003), mas não é isso que se observa ao se inventariar a arborização das cidades brasileiras, como é o caso de Uberlândia. Nas praças do bairro Jaraguá foi

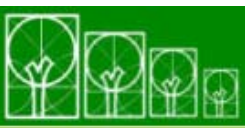

$\mathbf{S} \cdot \mathbf{B} \cdot \mathbf{A} \cdot \mathbf{U}$ Soc. Bras. de Arborização Urbana 
constatada a predominância de espécies exóticas, com 63,73\% dos indivíduos arbóreos (Tabela 1).

A crescente substituição da flora nativa por plantas exóticas altera o ambiente natural que resta nos centros urbanos. Agravamento maior ocorre quando algumas espécies exóticas introduzidas na arborização são invasoras biológicas (SILVA et al., 2008a). Essas espécies podem causar diversos danos ao ambiente, como a perda da biodiversidade; modificações dos ciclos; características naturais dos ecossistemas atingidos; alteração fisionômica da paisagem natural, dissociando o local da região fitoecológica onde se insere e, algumas vezes, consequências econômicas vultosas (ZILLER, 2001; MACHADO et al., 2006).

A predominância de plantas exóticas está representada pela Figura 2, e conclui-se que promove a competição com as espécies nativas por polinizadores e dispersores, de acordo com Silva et al. (2008a). No caso, as plantas nativas podem estar perdendo a "disputa", por estarem em menor número de indivíduos e muito dispersas, reduzindo o poder de atração dessas espécies.

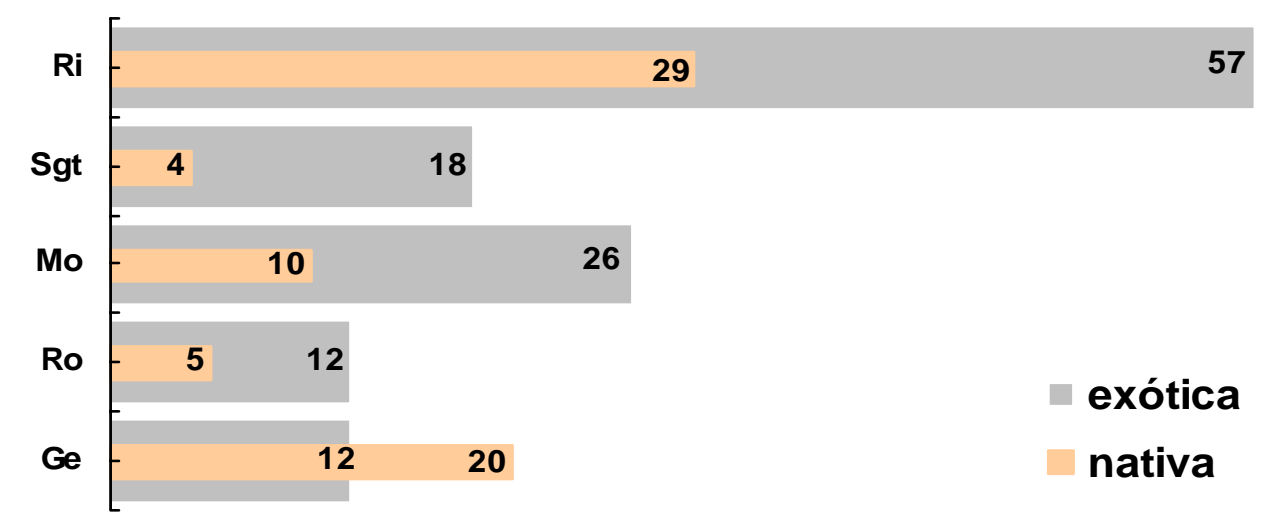

FIGURA 2 - Quantidade de espécies nativas e exóticas nas cinco praças do bairro Jaraguá.

Neste estudo de caso, mesmo ocorrendo maior presença de espécies nativas (11 nativas e 10 exóticas) e também serem a maioria das espécies em três praças (Tabela 1), tal fato não favorece a atração e manutenção da fauna, devido ao baixo número de indivíduos e a distribuição irregular, nas praças, de árvores como Licania tomentosa, com apenas um indivíduo; Sterculia chicha, com dois; Anacardium sp., Jacaranda mimosifolia, Ceiba speciosa, Psidium guajava e Cecropia holole., com três indivíduos cada. Somente a 
Praça Gefferson Guimarães da Silva apresentou maior número de plantas nativas (20 indivíduos de sete espécies nativas e 12 indivíduos de apenas uma espécie exótica).

Quanto ao porte das espécies vegetais, destaca-se o item médio porte (entre 3 e 6 m) como o mais frequente, com 78 indivíduos (Figura 3). Os valores acentuados, encontrados nas categorias pequeno e médio porte, devem-se a um processo muito lento de arborização das praças do bairro Jaraguá promovido pela prefeitura, iniciado há cerca de 10 anos, e ainda não concluído. O número reduzido de mudas pode indicar a falta de participação da população local na arborização, e de planejamento a longo prazo da arborização realizado pela PMU que, apesar de doar mudas à comunidade local, produzidas no Horto Florestal Municipal, as produz em quantidade inferior à demanda e do crescimento urbano.

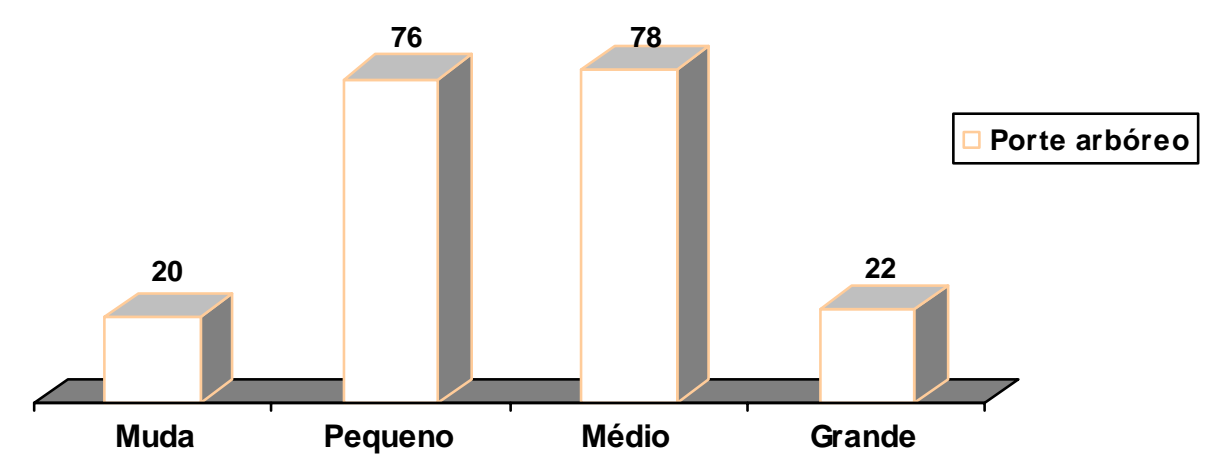

FIGURA 3 - Frequência das classes de altura total observada na arborização das praças do bairro Jaraguá. 


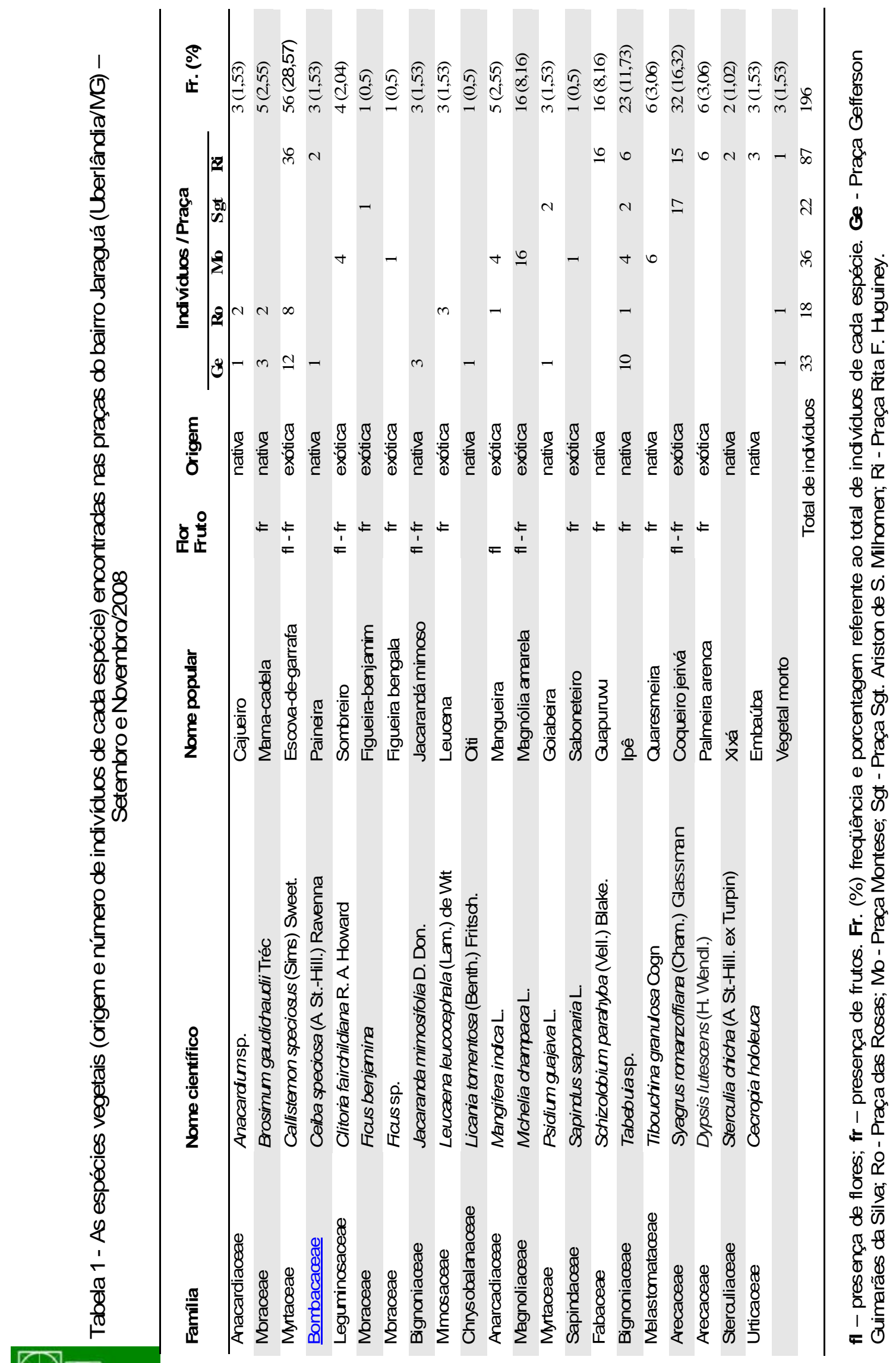


Na sua maioria, a arborização das praças do bairro Jaraguá se encontra em bom estado de conservação (Figura 4), sendo baixo o índice de ocorrência de pragas e doenças. Os danos físicos provocados por vandalismo (quebra de galhos e mudas) e podas inadequadas, tiveram grande influência na classificação físico sanitária.

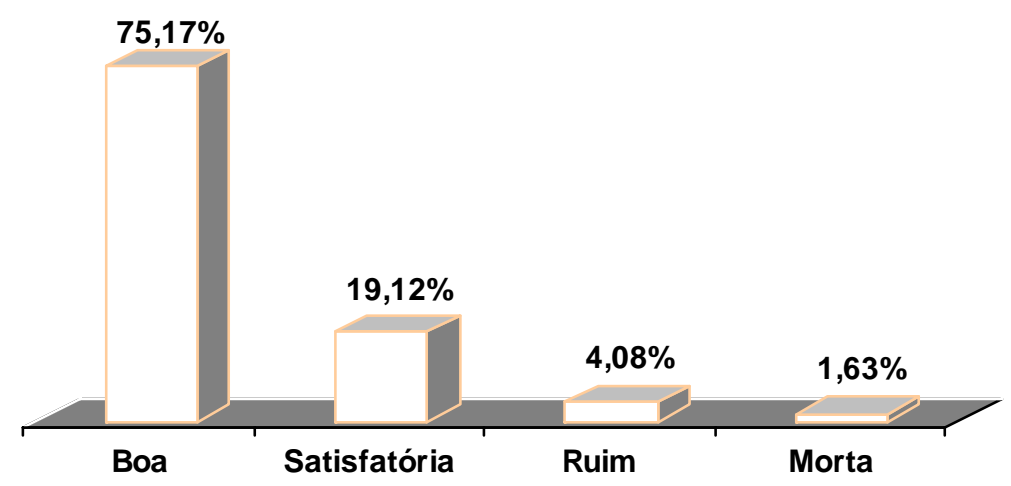

FIGURA 4 - Aspectos físicos e sanitários da arborização das praças do bairro Jaraguá.

A falta de participação da comunidade nos programas de arborização de ruas e a falta de tomada de consciência sobre a importância das árvores no ambiente urbano geram sérios prejuízos aos plantios (MILANO, 1987). As podas drásticas e mal conduzidas foram identificadas também na arborização da cidade de Curitiba, sendo um problema para a arborização (TRINDADE; ROCHA, 1990), pois após a poda drástica ocorre brotação vigorosa dos galhos aumentando seu crescimento e descaracterizando a espécie (BALENSIEFER, 1987).

Como as áreas de estudo não são conflitantes com as estruturas urbanas (edificações, rede elétrica) uma hipótese a ser considerada para a prática de podas drásticas é o fato de serem mal iluminadas tornando as áreas susceptíveis a prática de roubos, sendo as podas uma questão de segurança pública. Nesse sentido, cita-se o exemplo da cidade de Maringá (PR), que abaixou as luminárias e colocou duas luminárias em cada poste (MILANO, 1988). 


\section{CONSIDERAÇÕES FINAIS}

A arborização das praças do bairro Jaraguá apresenta diversos problemas (como predomínio de espécies exóticas, vandalismo e podas irregulares), relacionados à abundância e escolha das espécies utilizadas. Dentre os problemas observados está a alta frequência de espécies exóticas, fato que torna ineficiente a arborização local quanto a manutenção da biodiversidade regional.

O grande número de indivíduos exóticos pode demonstrar uma ausência de preocupação com a conservação da flora nativa, sendo assim, ressalta-se que um futuro planejamento da (re) arborização, deverá contribuir para a preservação das espécies nativas, sobretudo, as do Cerrado, por ser o bioma da região, e que está constantemente ameaçado pelas ações antrópicas.

Como estratégia para melhorar a arborização das praças do bairro Jaraguá, sugerese a implementação de um plano diretor municipal para a arborização urbana, em escala de detalhe, coordenada pela PMU, estabelecendo regras, realizando acompanhamento e controle de maneira efetiva. O desenvolvimento de um programa de educação ambiental junto à comunidade seria importante para a implementação do plano diretor para a arborização.

\section{REFERÊNCIAS BIBLIOGRÁFICAS}

ARAÚJO, G.M., NUNES, J.J., ROSA, A.G. \& RESENDE, E.J. Estrutura comunitária de vinte áreas de cerrados residuais no Município de Uberlândia, MG. Daphne, Belo Horizonte, v.7, n.2, p.7-14, 1997.

ARAÚJO, G. M.; BARBOSA, A. A.; AMARAL, A. F. Composição florística de veredas no Município de Uberlândia, MG. Revista Brasileira de Botânica. São Paulo, v.25, n.4, p.475493, dez. 2002.

BALENSIEFER, M. Poda em arborização urbana. Curitiba: ITCF, 1987, 27 p.

BIORDI, D.; LEAL, L. Caracterização das plantas produzidas no horto municipal da Barreirinha - Curitiba/PR. Revista da Sociedade Brasileira de Arborização Urbana, Piracicaba, v.3, n.2, p. 20-36, jun. 2008.

BLUM, C.T.; BORGO, M.; SAMPAIO, A.C.F. Espécies Exóticas Invasoras na Arborização de Vias Públicas de Maringá-PR. Revista da Sociedade Brasileira de Arborização Urbana, Piracicaba, v.3, n.2, p.78-97, jun. 2008. 
BRASIL. Lei $\mathbf{n}^{\circ}$ 6.766, de 19 de Dezembro de 1979, dispõe sobre o Parcelamento do Solo Urbano. Disponível em <http://www.planalto.gov.br/ccivil/LEIS/L6766.htm>. Acesso em: 01 out. 2008

BRITO, J.L.S.; PRUDENTE, T.D. Análise temporal do uso do solo e cobertura vegetal do município de Uberlândia-MG, utilizando imagens ETM+/ Landsat 7. Sociedade \& Natureza, Uberlândia, v. 17, n 32, p. 37-46, jun. 2005.

CAVALHEIRO, F.; DEL PICCHIA, P.C.D. Áreas Verdes: conceitos, objetivos e diretrizes para o planejamento. In: Congresso brasileiro sobre arborização urbana, I,. Anais I e II. Vitória/ES, 1992. p. 29-35.

CRUZ, P.M.F.; SOUSA, H.A.; CARVALHO, J.O.P.; BRITO, J.S. Análise quali-quantitativa da arborização urbana da Avenida Marechal Castelo Branco em Teresina-Piauí. III Congresso de Pesquisa e Inovação da Rede Norte Nordeste de Educação Tecnológica. Fortaleza CE, 2008.

DANTAS, I.C.; SOUZA, C.M.C. Arborização urbana na cidade de Campina Grande - PB: inventário e suas espécies. Revista de Biologia e Ciências da Terra. João Pessoa-PB, v.4, n.2, set. 2004 .

DEMATTÊ, M.E.S.P. Princípios de paisagismo. Jaboticabal: Funep, 1997. 104p.

GREY, G. W.; DENEKE, F. J. Urban Forestry. 2.ed. New York: John Wiley, 1986. 299p.

GRIFFITH, J.J.; SILVA, S.M.F. Mitos e métodos no planejamento de sistemas de áreas verdes. In: ENCONTRO NACIONAL SOBRE ARBORIZAÇÃO URBANA, 2., 1987, Maringá. Anais... Maringá: Imprensa da Prefeitura Municipal, 1987. p. 34-42.

GUIA SEI UBERLÂNDIA 2008/2009. Sociedade Anônima Brasileira de Empreendimentos, Uberlândia, 2008.

INSTITUTO BRASILEIRO DE GEOGRAFIA E ESTATÍSTICA - IBGE. cidades@ Disponível em: <http://www.ibge.gov.br/home/estatistica/populacao/contagem2007/contagem.pdf>. Acesso em: 18 set. 2008.

LIMA, A.M.L.P.; CAVALHEIRO, F.; NUCCI, J.C.; SOUZA, M.A.L.B.; FIALHO, N.O ; DEL PICCHIA, P.C.D. Problemas de utilização na Conceituação de termos como espaços livres, áreas verdes e correlatos. In: Congresso Brasileiro sobre Arborização Urbana, 2,. 1994a, São Luiz. Anais. São Luiz/MA, 1994a. p. 539-550.

LIMA, A. M. L. P., COUTO, H. T. Z., ROXO, J. L. C. Análise de espécies mais freqüentes da arborização viária, na zona urbana central do município de Piracicaba/SP. In: CONGRESSO BRASILEIRO DE ARBORIZAÇÃO URBANA, 2., 1994, São Luis. Anais... São Luís/MA, 1994b. p. 555-573.

MACHADO, P. A. L. Direito ambiental brasileiro. 5a. edição, São Paulo: Malheiros Editores, 1995. $696 \mathrm{p}$.

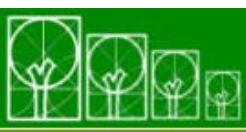

S $\cdot \mathbf{B} \cdot \mathbf{A} \cdot \mathbf{U}$ Soc. Bras. de Arborização Urbana 
MACHADO, R. B. B.; MEUNIER, I. M. J.; SILVA, A. J. A.; CASTRO, A. A. J. F. Árvores nativas para a arborização de Teresina/PI. Revista da Sociedade Brasileira de Arborização Urbana, Piracicaba, v. 1, n. 1, p. 10-18, 2006.

MILANO, M.S. O planejamento da arborização, as necessidades de manejo e tratamentos culturais das árvores de ruas de Curitiba, PR. Floresta, Curitiba, v.17, n.12, p.15-21, jun./dez.1987.

MILANO, M.S. Avaliação quali-quantitativa e manejo da arborização urbana: o exemplo de Maringál PR. Curitiba, 1988, 120 p. Tese (Doutorado em Engenharia Florestal) Setor de Ciências Agrárias, UFPR, Curitiba, 1988.

MILANO, M.S.; DALCIN, E.C. Arborização de vias públicas. Rio de Janeiro: Light, 2000. 226p.

NUCCl. J.C. Qualidade ambiental \& adensamento urbano: um estudo de ecologia e planejamento da paisagem aplicado ao distrito de Santa Cecília (MSP). São Paulo: Humanitas/FFLCH/USP, 2001. 234 p.

OLIVEIRA, C.H. Planejamento ambiental na cidade de São Carlos/SP com ênfase nas áreas públicas e áreas verdes: diagnóstico e propostas. São Carlos, 1996, 181 p. Dissertação (Mestrado) UFSCar, São Carlos, 1996.

PIRES, N.A.M.T.; MELO, M.S.; OLIVEIRA, D.E.; SANTOS, S.X. Diagnóstico da arborização urbana do município de Goiandira, Goiás. Revista Brasileira de Biociências, Porto Alegre, v. 5, supl. 1, p. 537-539, jul. 2007.

PORTO ALEGRE. Secretaria Municipal do Meio Ambiente. Plano Diretor de Arborização de Vias Públicas. Porto Alegre, 2000. 204 p.

REIS, A.; ANJOS, A.; LEISSA, A. P.; BECHARA, F. C. Critérios para a seleção de espécies na arborização urbana ecológica. Sellowia, Itajaí, v.53, n.55, p. 51-67, 2003.

ROCHA, R. T.; LELES, P. S. S.; OLIVEIRA NETO, S. N. Arborização de vias públicas em Nova Iguaçu: o caso dos bairros Rancho Novo e Centro. Revista Árvore. Viçosa, v.28, n.4, p. 599-607, jul./ago. 2004.

SANTOS, A.R.; BERGALLO, H.G.; ROCHA, C.F.D. Paisagem urbana alienígena. Revista Ciência Hoje, Rio de Janeiro, v. 41, n 245, p. 68-70, jan./fev. 2008.

SANTOS, D.G.; MAZZEI, K., PINA, J.H.A. Qualidade ambiental e parques urbanos - um índice de áreas verdes (IAV) por habitante para Uberlândia/MG em 2007. In: XIII CONGRESSO BRASILEIRO DE ARBORIZAÇÃO URBANA, 2009, Rio Branco. Anais... Rio Branco, 2009. 1 CD-ROM.

SANTOS, N.R.Z. dos; TEIXEIRA, I.F. Levantamento quantitativo e qualitativo da arborização do Bairro Centro da cidade de Santa Maria-RS. In: ENCONTRO NACIONAL SOBRE ARBORIZAÇÃO URBANA, 1990, Curitiba. Anais...Curitiba: FUPEF, 1990. 368 p. p. 263276. 
Avaliação qualitativa da arborização da cidade de Bento Gonçalves, RS. Ciência Florestal, Santa Maria, v.1, n.1, p.88-99, 1991.

Arborização de vias públicas: ambiente $x$ vegetação. $1^{\mathrm{a}}$ ed. Porto Alegre: Instituto Souza Cruz/Ed. Pallotti, 2001. 135 p.

SECRETARIA MUNICIPAL DE PLANEJAMENTO URBANO E MEIO AMBIENTE <www.uberlandia.mg.gov.br/.../planejamento urbano/pop oeste 2007.xls>. Acesso em: 1 dez. 2008.

SILVA, A. G. Avaliação da arborização no perímetro urbano de Cajuri - MG, pelo Método da Tabela Sintético. Viçosa, 2000. 150 p. Dissertação (Mestrado em Ciência Florestal) - UFV, Viçosa, 2000.

SILVA, E. M. da; ASSUNÇÃO, W. L. O Clima na cidade de Uberlândia - MG. Sociedade \& Natureza, Uberlândia, v.16, n.30, jun. 2004.

SILVA, G.A.; GONÇALVES, W.; LEITE, G.H.; SANTOS, E. Comparação de três métodos de obtenção de dados para avaliação quali-quantitativa da arborização viária, em Belo Horizonte - MG. Revista da Sociedade Brasileira de Arborização Urbana, Piracicaba, v.1, n.1, 2006.

SILVA, L.M.; RODIGHIER, D.A.; HASSE I.; CADORIN D.A. Arborização dos Bairros Pinheiros, Brasília e Bancários em Pato Branco/PR. Scientia Agraria, Curitiba, v.9, n.3, p.275-282, 2008a.

SILVA, M.D.M.; SILVEIRA, R.R.; TEIXEIRA, M.I.J.G. Avaliação da arborização de vias públicas de uma área da região oeste da cidade de Franca/SP. Revista da Sociedade Brasileira de Arborização Urbana, Piracicaba, v.3, n.1, p. 19-35, mar. 2008b.

SILVA, V. A. Geografia do Brasil e Geral: povos e territórios. São Paulo: Escala Educacional, 2005. 400p.

SILVEIRA, G.; BARROS, M.V.F. Perfil geoambiental de praças: região norte na cidade de Londrina-PR. Semina: Ciências Exatas e Tecnológicas, Londrina, v. 22, p. 63-71, dez. 2001.

TEIXEIRA, I.F. Análise qualitativa da arborização de ruas do conjunto habitacional Tancredo Neves, Santa Maria - RS. Ciência Florestal, Santa Maria, v. 9, n. 2, p. 9-21, 1999.

TOLEDO, F.S.; SANTOS, D.G. Espaços livres de construção. Revista da Sociedade Brasileira de Arborização Urbana, Piracicaba, v.3, n.1, p. 73-91, mar. 2008.

TOLEDO, F.S.; MAZZEI, K.; SANTOS, D.G. Um índice de área verde (IAV) para a cidade de Uberlândia/MG. Revista da Sociedade Brasileira de Arborização Urbana, Piracicaba, v.4, n.3, p. 86-97, set. 2009. 
TRINDADE, A. V. C.; ROCHA, M. P. da. Avaliação da situação fitosanitária das árvores de praça em Curitiba. In: ENCONTRO NACIONAL SOBRE ARBORIZAÇÃO URBANA, 1990, Curitiba. Anais... Curitiba: FUPEF, 1990, 368 p., p. 324-330.

UBERLÂNDIA. Dados sobre espécies invasoras ou potencialmente invasoras. Disponível em: <http://www3.uberlandia.mg.gov.br/secretaria.php?id=17\&id_cg=162>. Acesso em: 01 out. 2008

YAMAMOTO, M.A.; SCHIMIDT, R.O.L.; COUTO,H.T.Z.; SILVA FILHO,D.F. Árvores Urbanas. Piracicaba 2004. Disponível

<http:///mq.esalq.usp.br/ dfsilva/arvores_urbanas.pdf>. Acesso em: 8 nov. 2008.

ZILLER, S. R. Plantas exóticas invasoras: a ameaça da contaminação biológica. Revista Ciência Hoje, Rio de Janeiro, n. 178, p. 77-79. dez. 2001. 